\title{
Graduate Education Policy Framework for Developing Countries
}

\author{
ROBERTO N. PADUA \\ rnpadua@yahoo.com \\ TERESITA T. TUMAPON \\ ttumapon@gmail.com \\ MARIANO M. LERIN \\ president_liceo@yahoo.com.ph
}

Date Submitted: August 18, 2007

Final Revision Accepted: November 15, 2007

\begin{abstract}
The paper examines worldwide patterns of operations of graduate education using 40 countries' data on advanced education focusing on contexts, inputs, processes and outcomes of graduate education with a view to deriving sets of national policies in advanced educatFinal Word Formation for the Philippines. In all, 10 variables were used as multivariate inputs to a cluster analysis algorithm that aims to cluster countries in terms of a $10 \times 10$ similarity matrix with a hierarchical cluster method. Data per variable needed in the cluster analysis were obtained from the net and confirmed through e-mail communication with key informants in at least 20 of the 40 countries identified. Results revealed that developing countries' graduate education differed from the graduate education of developed and less developed countries in terms of : contexts (mainly full-time or part-time, external support to graduate education), inputs (admission standards, controls), process (academic advising, research focus, graduate teaching, quality assurance mechanisms), and outcomes (employment of Ph.D.'s, indicative economic contributions of Ph.D.'s). On the basis of the hierarchical cluster analysis performed, policy recommendations are given to enhance the delivery of graduate education in the Philippines and to sharpen its contribution to national development.
\end{abstract}

Key words - cluster analysis, hierarchical method, graduate education, systems analysis, policy framework 


\section{INTRODUCTION}

Graduate education is a relatively young addition in the landscape of higher education; yet, its quality also appears to define the overall perception of quality for the entire educational system itself. Developed countries, for instance, have higher education systems that are worldwide respected which can be mainly attributed to their extremely competitive, refined graduate education systems. Without fear of contradiction, it may therefore be surmised that graduate education lies at the apex of the entire higher education system (CHED-OPPRI, 2001).

While generally recognized as the main source of scientific and technological breakthroughs, graduate education is also the least structured among the different subsystems of educational systems in the world. Graduate education is an educational subsystem that possesses the following characteristics: (a) emphasis on research and independent study, (b) relatively unstructured curricula and course of study that mainly support student research, (c) minimal faculty supervision on classroom work, and (d) high reliance on peer review for quality assurance. Within this rather broad characterization of graduate education emerges three distinct types of graduate programs: (a) graduate programs that are essentially research-based with practically no course work relying mainly on specialized seminar courses that relate directly to the students' research, (b) graduate programs where there is heavy reliance on course work (actual classroom lectures) and where research constitutes a mere $10 \%$ of the entire program of study i.e. thesis/dissertation writing phase only, and (c) graduate programs where there is practically no research and students concentrate on course work and lectures (often called "practitioner's degree").

The last category of graduate programs appears to have been developed in response to the growing clamor for more advanced degrees to satisfy requirements of regulatory bodies and agencies and in situations where research is perceived to be a mere barrier to that attainment of a master's or doctoral degree (www.aau.ac).

A nation's system of graduate education delivery depends on its level of development and need for high level of expertise in the attainment of its national goals and objectives. For instance, graduate education in the United States is widely recognized as the best in the world, yet it is far from perfect and will remain in a leadership position only by continual self-examination and improvement. Criticisms commonly heard today include overproduction of Ph.D.s; narrow training, emphasis on research over teaching, use of students to meet institutional needs at the expense of sound education, and insufficient mentoring, career advising, and job placement assistance. Its emphasis on the production of highly qualified Ph.D.'s with very narrow specialized training 
stems from the demand of large corporations and business establishment in the US requiring the top caliber research expertise of young Ph.D.'s, e.g., genetic research, pharmacological research, computer-related research, etc. (Association of American Universities, Committee on Graduate Education, 2000).

On the other hand, less developed countries, whose needs for highly specialized Ph.D.'s are not as urgent, tend to de-emphasize narrow and specialized training in research. Instead, graduate education in these countries is perceived to be an opportunity to augment a rather inadequate training and instruction at the undergraduate level.

Consequently, high variance is noted in the type and quality of graduate education outputs of various universities in different parts of the world. This paper posits that such " variances may be essentially explained by the nation's level of development and national priorities and perspectives that influence the context, inputs, processes, and outputs of their graduate education programs". Section 2 provides the research and analytical framework; section 3 provides the cluster analysis results on 40 countries included in the study; and section 4 provides conclusions and policy recommendations for consideration by the Philippine Commission on Higher Education.

\section{RESEARCH DESIGN AND FRAMEWORK}

The study is anchored on the premise that variances in the contexts, inputs, processes, outputs, and outcomes of graduate education in different universities in various parts of the world are attributable to the varying national perspectives held by the countries' leadership in education. Ultimately, such national perspectives are motivated by mainly economic, social or political considerations in pursuit of the collective ideals of the nations. The nations' differential characteristics in terms of inputs, processes, outputs, and outcomes of graduate education will, therefore, form natural bases with which to cluster or aggregate the countries. To this end, the study utilized the descriptive analytical method of research, extensively utilizing the method of cluster analysis.

The term cluster analysis [first used by Tryon (1939) cited by Johnson and Wichern (1998)]encompasses a number of different algorithms and methods for grouping objects of similar kind into respective categories. A general question facing researchers in many areas of inquiry is how to organize observed data into meaningful structures, that is, to develop taxonomies. In other words cluster analysis is an exploratory data analysis tool that aims at sorting different objects into groups in a way that the degree of association between two objects is maximal if they belong to the same group and minimal otherwise. Given the above, cluster analysis can be used to discover structures in data without providing an explanation/interpretation. In other words, cluster analysis simply discovers structures in data without explaining why they exist. At the 
Liceo Journal of Higher Education Research

initial stage, all the observations represent their own clusters. Using a distance measure, those that are within a specified distance from each other are grouped together. In this study, the weighted averages (centroid) of the groups are used to further group the observations into larger clumps. The process is built in almost all modern statistical software packages.

\section{Variables Used for Cluster Analysis}

The following variables were used as basis for k-means clustering:

Context: x1: graduate student status (mainly part-time/full-time), x2: federal /government support to graduate research (from low to high); Input: x3: admission standards(rejection rate), x4: graduate faculty qualification (\%doctorates); Process: academic advising (present or absent),x6: research-based or non-research based curricula, x7: quality assurance system (voluntary or required); Output: x8: volume of Ph.D.'s produced to number of undergrads; Outcome: x9: \% employment of Ph.D.'s, x10: \% Ph.D.'s employed in other economic sectors.

\section{RESULTS AND DISCUSSION}

Data on the ten (10) variables obtained through data mining and correspondences with key informants from the forty (40) countries involved in the study were subjected to cluster analysis using the (weighted) average hierarchical cluster algorithm with $\mathrm{k}=$ 3 mean (centroids). Figure 1 shows the resulting dendrogram.

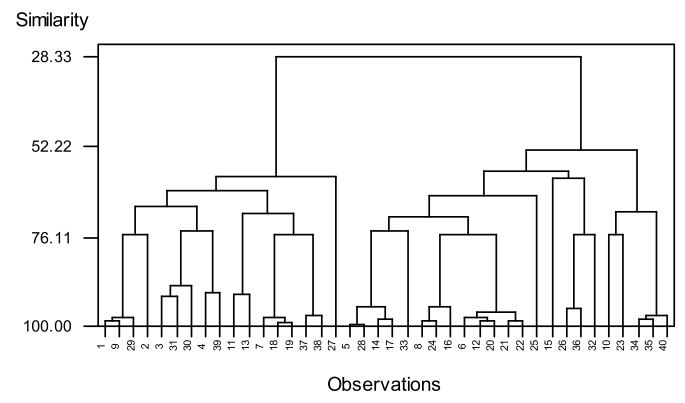

Figure 1: Dendrogram of forty (40) countries

Three (3) clusters were identified as shown in Table 2 with seventeen (17) countries belonging to cluster 1 , eighteen (18) in cluster 2, and five (5) in cluster 3 . Countries belong to the same cluster are more homogenous in terms of the variables considered than are countries belonging to other clusters. The countries that belonged to each cluster are also shown in the same table. It may be noted that the Philippines is found in cluster 1 in the same league as Malaysia, Indonesia, Thailand, India, Brazil, Italy, Taiwan, and Argentina. The United States is located in cluster 2 together with Ireland, 
Finland and the other Nordic countries, France, Japan, Austria, Israel, South Korea, Germany, and China. The third cluster has Spain, South Africa, Russia, Poland, and Hungary.

Table 2: Clustering of countries based on the cluster algorithm

\begin{tabular}{|c|c|c|c|c|}
\hline & $\begin{array}{l}\text { Number of } \\
\text { observations }\end{array}$ & $\begin{array}{l}\text { Within cluster } \\
\text { sum of squares }\end{array}$ & $\begin{array}{l}\text { Average distance } \\
\text { from centroid }\end{array}$ & $\begin{array}{l}\text { Maximum distance } \\
\text { from centroid }\end{array}$ \\
\hline Cluster1 & 17 & 15.077 & 0.927 & 1.318 \\
\hline Cluster2 & 18 & 15.954 & 0.896 & 1.776 \\
\hline Cluster3 & 5 & 2.142 & 0.619 & 1.017 \\
\hline \multicolumn{5}{|c|}{$\begin{array}{l}\text { Cluster 1: Philippines, Malaysia, Indonesia, Thailand, India, Argentina, Surinam, Pakistan, Brazil, Italy, Taiwan, Myanmar, Laos, } \\
\text { Bangladesh, Cuba, Ethiopia, Iran } \\
\text { Cluster 2: Ireland, Australia, New Zealand, Austria, Finland, Israel, Vietnam, Japan, Denmark, Norway, Belgium, France, } \\
\text { Kingdom of Saudi Arabia, China, South Korea, United States of America, Germany } \\
\text { Cluster 3: Spain, South Africa, Russia, Poland, Hungary }\end{array}$} \\
\hline
\end{tabular}

With the exception of Vietnam, countries in cluster 2 have developed economies while countries in cluster 1 (where the Philippines is located) have either a developing or less developed economies. On the other hand, countries categorized in cluster 3 have economies similar to cluster 1 yet may actually be more similar to cluster 2 in terms of the variables considered in clustering them as evidenced by the cluster's distance from the centroid. Further analysis is needed in order to identify the variable or driving variables that forced these countries into the third cluster as illustrated in the next subsection.

\section{Cluster Graduate Education Outcomes}

The graduate education outcomes of the clusters were analyzed in terms of the last two variables: x9 (percentage of employment of Ph.D.'s) and x10 (percent of Ph.D.'s employed in other economic sectors). While all the clusters have generally high values for $x 9$, i.e. high employment profile for Ph.D. graduates, they vary significantly in terms of $x 10$ (percent of employment in other economic sectors). The ratio x10: x9 expressed in percent provides a good descriptive picture of the extent to which the outputs of advanced education are put to more economically productive use by the different countries. Table 3 summarizes this information:

Table 3: Graduate education outcome indicators by clusters

\begin{tabular}{llcl}
\hline \hline Cluster & $\begin{array}{l}\text { X9 } \\
\% \text { Ph.D. Employed }\end{array}$ & $\begin{array}{l}\text { x10 } \\
\% \text { Ph.D. Employed } \\
\text { Other Econ. Sector }\end{array}$ & $\begin{array}{l}\text { Ratio } \\
\text { x10:x9\% }\end{array}$ \\
\hline \hline 1 & 0.8429 & 0.1478 & $17.53 \%$ \\
2 & 0.9497 & 0.3728 & $39.25 \%$ \\
3 & 0.9000 & 0.1160 & $12.89 \%$ \\
\hline \hline
\end{tabular}

Tabular values indeed indicate that clusters 1 and 3 are more similar in terms of the contribution of Ph.D.'s to the various countries' economies $(17.53 \%$ for cluster 1 and $12.89 \%$ for cluster 3). Ph.D.'s have maximal economic contribution to countries belonging to cluster 2 (more than double the contribution of Ph.D.'s in the other two 
Liceo Journal of Higher Education Research

clusters). It can be surmised from this information that Ph.D. graduates from clusters 1 and 3 tend to be employed in universities and academic institutions more than the cluster 2's Ph.D.'s who venture into R \& D jobs in the other economic sectors of their countries. Consequently, both the technological advancement and economic development of nations in cluster 2 are significantly higher than in the countries belonging to clusters 1 and 3.

Unfortunately, it is also noted that opportunities for PhD graduates to participate in the R \& D activities of large business corporations and firms are severely limited in countries found in clusters 1 and 3. Such large corporations tend to locate their offshore $\mathrm{R} \& \mathrm{D}$ Divisions in cluster 2 countries where the production of high quality PhD's appears to be ensured. As a result, PhD graduates of clusters 1 and 3 countries find themselves teaching or doing research in universities and academic institutions therein located. Furthermore, since the needs of universities and academic institutions are really only for "good teachers", research becomes a mere appendage to most graduate programs in clusters 1 and 3.

\section{Policy Variables}

Next examined were the variables used for contexts, inputs, processes, and outputs of graduate education programs in the various clusters to explain the graduate education outcomes noted. Table 4 shows the centroids (weighted averages) of the aforementioned variables per cluster.

Table 4. Centroids of policy variables by cluster

\begin{tabular}{|c|c|c|c|c|}
\hline Cluster Cen & & & & \\
\hline Variable & Cluster1 & Cluster2 & Cluster3 & Grand centrd \\
\hline Studes ( & 0.0588 & 1.0000 & 1.0000 & 0.6000 \\
\hline Supp & 1.0588 & 3.5000 & 2.0000 & 2.2750 \\
\hline Rejectio & 0.1518 & 0.4817 & 0.4800 & 0.3412 \\
\hline$\%$ Doctor & 0.5382 & 0.9267 & 0.8640 & 0.7537 \\
\hline Acad adv & 0.5294 & 0.9444 & 1.0000 & 0.7750 \\
\hline Research & 1.5882 & 2.6667 & 2.6000 & 2.2000 \\
\hline Qual. As & 0.3529 & 0.6667 & 0.2000 & 0.4750 \\
\hline $\mathrm{Ph} . \mathrm{D} / \mathrm{Und}$ & 0.0698 & 0.1113 & 0.0818 & 0.0900 \\
\hline \% Employ & 0.8429 & 0.9497 & 0.9000 & 0.8981 \\
\hline$\%$ Other & 0.1418 & 0.3722 & 0.1160 & 0.2423 \\
\hline
\end{tabular}

Context

Cluster 1 countries have graduate programs that cater mainly to part-time (weekend) graduate students while graduate students from countries in clusters 2 and 3 are mainly full-time students. The full-time status of graduate students in the other two clusters allows them to better concentrate on their studies. Similarly, there appears to be minimal external support for research (from government or external agencies) for graduate programs in countries belonging to cluster 1 where, in the same context, graduate programs in cluster 2 countries obtain greater support for research either 
from federal or government coffers or from other external agencies.

Inputs

Clusters 2 and 3 countries have highly selective graduate programs with rejection rates hovering close to $50 \%$, whereas countries in cluster 1 have graduate programs that admit almost everyone who applies for admission (rejection rate of only $15 \%$, on the average). Consequently, graduate programs in clusters 2 and 3 have better quality graduate students who benefit most from advanced training and research. This could, in part, be explained by the level of the nations' economic development, and, in part, by the overall philosophy adopted for higher education, i.e., massification vs. selectivity in higher education.

Similarly, the percentages of Ph.D.'s teaching in graduate programs for cluster 2 countries are in the high 90's while only a little over $50 \%$ of the faculty of graduate programs in cluster 1 countries hold doctorate degrees. If a doctorate degree possessed by the teachers were to be a measure of the quality of instruction being given by these countries, then cluster 1 countries would be way off the desired mark in this dimension.

\section{Processes}

Graduate programs in cluster 2 countries have, with high probability, an academic advising system for graduate students. On the other hand, such an academic advising service may be found in universities found in cluster 1 countries with $53 \%$ probability (like tossing a coin) - sometimes they do, sometimes they do not. Academic advising is a very important aspect of operating graduate programs for it serves several purposes. First, it helps the student plan a course of study with the guidance of an expert. Second, academic advisers are tasked to monitor and evaluate the progress of a graduate student. Finally, through academic advising the student is guided on possible adjustments and re-adjustments to this original plan or course of study based on performance.

Data likewise reveal that cluster 2 countries have predominantly research-based graduate curricula while those in cluster 1 either have pure coursework or a combination of $90 \%$ coursework and $10 \%$ research. Graduate students from cluster 2 countries are, thus, trained to be more independent than are students from cluster 1 countries.

Thirty five percent $(35 \%)$ of the countries in cluster 1 opted for voluntary accreditation of their graduate programs as a means to ensure quality while about twothirds $(66.67 \%)$ of the countries in cluster 2 have some form of voluntary accreditation among peer universities. However, since the norms and standards used in accreditation are, by nature, country-based (as there appears to be no international standard for graduate education that is universally accepted), the value of accreditation in a global analysis such as this cannot be accurately gauged. 


\section{Output}

The output indicator of graduate education used in this study is the ratio of the number of Ph.D.'s enrolled to the undergraduate enrollment in universities. Data reveal that such a ratio is high for countries belonging to cluster 2 ( 1 Ph.D. per 10 undergraduate students) while quite low for cluster 1 countries (1 Ph.D. per 30 undergraduate students).

\section{CONCLUSIONS}

Analysis of the worldwide patterns for advanced education reveals three distinct clusters of countries with the clustering mainly driven by the way that their advanced education outputs are being utilized to contribute to national economic development and by the countries' national perspectives on graduate education. More economically developed nations tend to be clustered together while the developing and less developed nations are similarly clustered together. The study found out that the clustering of countries may actually be attributed to the differential characteristics of graduate programs in these countries in terms of their contexts, inputs, processes, and outputs.

\section{POLICY RECOMMENDATIONS}

In view of these, the following policy recommendations are suggested for consideration by the Philippine Commission on Higher Education: The Commission on Higher Education may facilitate the crafting and definition of a national vision for graduate education outcomes similar to the clear and unequivocal national perspectives of developed nations, e.g., USA. Such a national vision translates into institutional policies on admission, processes and outputs for graduate education. The short basic education cycle of the Philippine educational system forces its higher education system to compensate by providing for general education courses in college curricula that could otherwise have been used for specialized trainings. Graduate level programs which presumably are highly specialized should therefore be made more intensive

To this end, full-time graduate studies need to be encouraged in order to ensure high quality training of specialists. In particular, graduate level scholarship programs in the $S \& T$ areas will have to be expanded and sustained in order to develop better equipped scientists and engineers to handle R \& D in business and industry. Advanced education, in general, needs to be more selective (at least a $33.33 \%$ rejection rate is desirable) in order for the country to benefit most out of its outputs. To this end, a national Graduate Record Examination (GRE) may be centrally administered by the Commission on Higher Education for this purpose. The national GRE coupled with the 
individual institutional admission requirements should be the bases for admission in graduate programs.

Research-based graduate curricula, particularly in the Science, Mathematics and Engineering, need to be supported by establishing more such programs in selected graduate schools in the country through special grants from the Commission on Higher Education. While some fields are oversubscribed e.g. $85 \%$ of all doctorate degrees are in the field of education and management, the $S \& \mathrm{~T}$ graduate programs are currently severely undersubscribed.

The processes adopted by recognized graduate schools in the Philippines need to be standardized in such a way that academic advising becomes an integral part of the process. As already mentioned, academic advising contributes to the overall quality of graduate education outcomes.

Research needs to be treated not as a mere appendage to graduate programs but as a centerpiece of all graduate programs. While the pressure to confer advanced degrees in a shorter period of time may be quite strong, producing advanced education graduates who cannot do independent work will, in the long run, be counterproductive to the Philippine higher education system.

\section{LITERATURE CITED}

CHED-OPPRI (2001), "Accomplishments of CHED: 1994-1999"

Johnson, R. and Wichern J.(1998). Applied Multivariate Statistical Analysis. New York: Wiley and Sons Inc.

\section{DATA MINING SOURCES}

http://www.open.ac.uk

http://www.aau.ac.in

http://www.graduate.japan

http://www.graduate.nordic

http://www.graduate.aust 